\title{
Is There an Association Between Duration of Untreated Psychosis and 24-Month Clinical Outcome in a First-Admission Series?
}

\author{
Thomas J. Craig, M.D., Evelyn J. Bromet, Ph.D., Shmuel Fennig, M.D., \\ Marsha Tanenberg-Karant, M.D., Janet Lavelle, M.S., and Nora Galambos, Ph.D.
}

\begin{abstract}
Objective: The authors examined the duration of untreated psychosis, defined as the interval from first psychotic symptom to first psychiatric hospitalization, in a county-wide sample of first-admission inpatients who had received no previous antipsychotic medication. Differences between diagnostic groups in 24-month illness course and clinical outcomes as well as relationships between outcomes and duration of untreated psychosis were evaluated. Method: The data were derived from subjects in the Suffolk County Psychosis Project who were diagnosed at 24-month follow-up according to DSM-IV as having schizophrenia or schizoaffective disorder $(\mathrm{N}=155)$, bipolar disorder with psychotic features $(\mathrm{N}=119)$, or major depressive disorder with psychotic features $(\mathrm{N}=75)$. Duration of untreated psychosis was derived from the Structured Clinical Interview for DSM-III-R, medical records, and information from significant others. Measures at 24-month follow-up included consensus ratings of illness course, Global Assessment of Functioning Scale scores for the worst week in the month before interview, and current affective and psychotic symptoms. Results: The median duration of untreated psychosis was 98 days for schizophrenia, 9 days for psychotic bipolar disorder, and 22 days for psychotic depression. Duration of untreated psychosis was not significantly associated with 24-month illness course or clinical outcomes in any of the diagnostic subgroups. Conclusions: Although these findings require replication in other epidemiologically based first-admission samples, at face value they do not support the suggestion of a psychotoxic effect of prolonged exposure to untreated psychosis.
\end{abstract}

(Am J Psychiatry 2000; 157:60-66)

ver the past four decades, several types of studies have addressed the importance of characteristics of illness onset in predicting outcome in schizophrenia. Until the mid-1980s, type of onset was included among a group of phenomena considered predictive of "good" versus "poor" prognosis schizophrenia in samples of patients diagnosed according to pre-DSM-III criteria

Received Dec. 7, 1998; revision received July 20, 1999; accepted July 21, 1999. From the Department of Veterans Affairs, Veterans Integrated Service, Network 3, Bronx, N.Y.; the Department of Psychiatry and Behavioral Science, State University of New York at Stony Brook; and Shelvata Hospital, Tel Aviv, Israel. Address reprint requests to Dr. Bromet, Department of Psychiatry, State University of New York, Putnam Hall-South Campus, Stony Brook, NY 11794-8790.

Supported by NIMH grant $\mathrm{MH}-44801$.

The authors thank the many mental health professionals in Suffolk County, project psychiatrists and staff, and especially the study participants and their families and friends for their efforts on this project.
$(1,2)$. In these studies, “acute” onset (e.g., the presence of active symptoms suggesting a schizophrenic illness for less than 6 months before the initiation of treatment) was grouped among the predictors of good outcome. A variant of this approach was used in the World Health Organization (WHO) Determinants of Outcome in Schizophrenia study (3), in which the onset variable was divided into three categories: acute (up to 1 week), subacute (1 week to 1 month), and gradual (exceeding 1 month from onset of symptoms to treatment). That study, which used ICD-9 and the computer algorithm CATEGO to define the diagnostic categories, found onset type to be one of the two most important predictors of 2-year outcome (the other was settingi.e., developed versus developing country). However, in the mid-1980s, retrospective studies found that the 6month duration of illness criterion required for the DSM-III diagnosis of schizophrenia reduced the number of patients considered to have an acute onset, mak- 
ing it more difficult to predict outcome in young patients with recent-onset schizophrenia $(4,5)$.

In a pivotal study of the effect of the duration of psychosis before first treatment on subsequent response to treatment, Crow et al. (6) found that firstadmission patients with CATEGO-diagnosed schizophrenia whose onset of psychotic symptoms preceded the initiation of antipsychotic medication by more than 1 year were significantly more likely to relapse during a 2-year follow-up than those whose symptoms were untreated for less than 1 year. In addition, a study of DSM-I-diagnosed schizophrenia found that patients randomly assigned to placebo treatment had a consistently worse long-term outcome despite the fact that they received antipsychotics after the completion of the initial experimental trial (7).

Crow et al. (6) suggested that the failure to initiate early treatment with antipsychotic medication might lead to the development of a higher susceptibility to relapse and argued against an earlier suggestion (preDSM-III) (8) that a subgroup of patients with schizophrenia might benefit from the withholding of antipsychotics. More recently, in a study of patients experiencing their first episode of schizophrenia diagnosed according to Research Diagnostic Criteria (RDC), Loebel et al. (9) found that the amount of time from onset of psychotic symptoms to initiation of antipsychotic treatment was a significant predictor of time to treatment response. These authors echoed the earlier concern of Crow et al. (6), stating that "these findings suggest that an active morbid process might occur during periods of acute symptoms or decompensation which, if not ameliorated by neuroleptic drug treatment, may result in lasting morbidity." Citing support from preclinical studies, they went on to hypothesize that "an extended period of dopaminergic neural dysfunction may result in a more severe, or less reversible, pathophysiologic condition." However, a recent report from the same study sample (10) found no significant association between duration of untreated psychosis and time to relapse, suggesting that the use of different outcome measures may give varying results.

Finally, based in part on these observations, concerns have been raised regarding the ethics of the use of placebo controls in experimental drug trials for disorders for which there is effective conventional treatment (11). Determination that withholding active antipsychotic treatment in a placebo-controlled study carries a risk of increasing the likelihood of poor outcome could have a substantial impact on the current strategy of developing new antipsychotic drugs.

The studies cited are noteworthy for their lack of consistency in the definition of "long" versus "short" duration of psychotic symptoms, ranging from 4 weeks $(3)$ to 6 months $(1,2)$ to 1 year $(6)$, and raising questions as to whether there might be a "threshold" duration period beyond which adverse outcome might be more likely to occur. Nevertheless, the finding on the toxic nature of untreated psychosis has led to a number of important early intervention programs (e.g., reference 12).

Since a number of reports have demonstrated that many patients diagnosed as having schizophrenia according to pre-DSM-III nosologic strategies would be diagnosed as having an affective disorder according to DSM-III criteria, it is striking that, to our knowledge, very little attention has been given to the possible relationship between duration of untreated psychosis and subsequent outcome in patients experiencing their first episode of affective psychosis. Is the finding specific to schizophrenia, or would the effect occur in other psychotic conditions as well?

In the present study, we attempted to confirm the predictive utility of duration of untreated psychosis in a longitudinal study of an epidemiologic cohort of first-admission patients with psychotic disorders. Consistent with previous research, duration of untreated psychosis was operationalized as the time between the occurrence of psychotic symptoms and entry into the hospital of patients who had received no previous antipsychotic treatment. In this article, we present differences in duration by diagnosis in relation to 24-month illness course and clinical outcomes.

\section{METHOD}

\section{Sample and Procedures}

The present sample is part of the Suffolk County, N.Y., cohort recruited between 1989 and 1995 from the 12 facilities in the county - six community hospital units, a university hospital unit, a VA hospital, an adult state psychiatric center, two private facilities (added in 1994), and a children's state psychiatric center. Inclusion criteria were ages 15-60; residence in Suffolk County; and clinical evidence of psychosis, prescription of neuroleptic medication, and/or a clinical discharge diagnosis indicating psychosis. Exclusion criteria were first psychiatric hospitalization more than 6 months before current admission, moderate or severe mental retardation, and an inability to speak English. An initial (baseline) interview usually took place in the hospital a week or two after admission. A complete description of the study was provided, and written informed consent was obtained for the interview and for review of medical records, talking with treating clinicians, and interviewing significant others. The 24-month follow-up interviews were conducted by the same interviewer when possible and took place primarily in the subjects' homes. In addition, interviewers maintained telephone contact every 3 months or periodically visited the home if the patient did not have a telephone. The overall response rate was $72 \%$ at baseline; 24 month follow-up contact was obtained for $89 \%$ of the sample.

The diagnostic assessment was conducted by trained master'slevel mental health professionals and included the Structured Clinical Interview for DSM-III-R (SCID) (13). The baseline SCID ratings combined symptom information obtained during the interview with material obtained from the medical record and the other sources. SCIDs were administered at the 6- and 24-month follow-ups. The specifics of the diagnostic procedure have been detailed in a previous report (14). Briefly, after the 6- and 24-month interviews, diagnoses were assigned by consensus of two to four project psychiatrists after discussion of all relevant clinical information and diagnostic criteria. The analysis reported in this article is based on the 24-month, longitudinal DSM-IV research diagnosis.

The target sample included 219 patients with schizophrenia or schizoaffective disorder, 139 with bipolar disorder with psychotic features, and 86 with major depressive disorder with psychotic features. In this report, we excluded patients who had received antipsychotic 
medications before their first hospitalization (61 patients with schizophrenia, 18 with bipolar disorder, and 11 with depression). In four additional cases (two with schizophrenia and two with bipolar disorder), we were unable reliably to date the onset of the psychosis. Thus, the analysis sample included 155 patients with schizophrenia or schizoaffective disorder, 119 with bipolar disorder with psychotic features, and 75 with major depressive disorder with psychotic features.

\section{Measures}

The length of untreated psychosis was defined as the interval from the occurrence of the first clear psychotic symptom to first psychiatric hospitalization. This onset date was synthesized from information obtained from the baseline and follow-up SCIDs, medical records, and significant others. The SCID interview included a chronology of each psychotic symptom. When new information on psychosis emerged during follow-up interviews, the onset date was revised accordingly.

At the 24-month diagnostic conference, consensus was reached on the classification of illness course based on the WHO 8-point system (3). For this report, patients with schizophrenia were grouped into three categories: those who had experienced one or more episodes followed by complete remission; those who had experienced one or more episodes followed by partial remission; and those who were continuously ill throughout the 24 months. Because the majority of the affectively ill patients achieved complete remission during the follow-up, they were divided into those with complete remission and those with incomplete or no remission. Other clinical outcomes included score on the Global Assessment of Functioning Scale for the worst week in the month before the 24-month interview; whether rehospitalized; average global ratings $(0=$ absent; $5=$ severe $)$ on the Scale for the Assessment of Positive Symptoms and the Scale for the Assessment of Negative Symptoms (15); scores on thought disturbance and anxiety/depression scales and excitement and grandiosity items on the Brief Psychiatric Rating Scale (16), Hamilton Depression Rating Scale score (17), and score on the self-report Beck Hopelessness Scale (18).

\section{Analysis}

We first examined differences among diagnostic groups in the interval from first psychotic symptom to hospitalization using survival analysis and step-wise Cox proportional hazards models to examine the effect of the demographic variables and diagnosis on the interval to hospitalization. Within the diagnostic groups, we examined the relationship between duration of untreated psychosis and 24-month course and outcome using survival analysis and analysis of variance after dividing the duration variable into relevant diagnosis-specific categories.

Finally, before undertaking the analysis, we examined whether treatment during the follow-up interval served as a confounder, i.e., whether it was related to the duration and outcome variables. The treatment variables considered were number of months receiving treatment during the 24-month follow-up and number of months receiving psychotropic medication during the 6 months preceding the 24-month follow-up. Neither treatment variable was significantly associated with duration of untreated psychosis (e.g., the correlations ranged from 0.01 for schizophrenia and 0.05 for both affective groups). Number of months receiving treatment was not significantly correlated with the clinical outcomes in the schizophrenia or major depression groups; however, among the subjects with bipolar disorder, those with better outcomes tended to receive less treatment. Overall, treatment did not function as a confounding variable.

\section{RESULTS}

\section{Characteristics of the Sample}

The median ages of the patients in the diagnostic groups were 26 years for those with schizophrenia, 27 for those with psychotic bipolar disorder, and 31 for those with psychotic depression $\left(\chi^{2}=5.9, \mathrm{df}=2, \mathrm{p}=0.05\right.$,
Kruskal-Wallis test). There were relatively more men with schizophrenia $(\mathrm{N}=103,66.5 \%)$ than with psychotic bipolar $(\mathrm{N}=57,47.9 \%)$ or depressive $(\mathrm{N}=30$, $40.0 \%)$ disorder $\left(\chi^{2}=17.4, \mathrm{df}=2, \mathrm{p}<0.001\right)$. The median ages of the men and women, respectively, were 25 and 28.5 for those with schizophrenia, 23 and 29 for those with bipolar disorder, and 27 and 33 for those with depression. Consistent with the age distributions, a larger proportion of the patients with schizophrenia $(79.4 \%$ [N=123]) had never married than those with bipolar disorder $(61.3 \%$ [ $\mathrm{N}=73])$ and those with depression $(54.7 \%[\mathrm{~N}=41])\left(\chi^{2}=17.7, \mathrm{df}=2, \mathrm{p}<0.001\right)$. Among the patients for whom data on socioeconomic status were available, relatively more of the patients with schizophrenia $(19.0 \%$ [N=27]) were from lower, "unskilled" social class households than those with bipolar disorder $(13.0 \%$ [N=15]) and those with depression $(11.3 \%[\mathrm{~N}=8])\left(\chi^{2}=17.3, \mathrm{df}=6, \mathrm{p}<0.01\right.$ for four occupational class groups). Relatively more of the schizophrenia group $(21.9 \%$ [N=34]) were African American than the bipolar group $(5.9 \%[\mathrm{~N}=7])$ and the depressed group $(6.7 \%[\mathrm{~N}=5])\left(\chi^{2}=18.7, \mathrm{df}=2, \mathrm{p}<\right.$ $0.001)$. There was no significant difference in DSM-III$\mathrm{R}$ lifetime substance use disorder $(70$ [45.2\%] of the patients with schizophrenia, 60 [50.4\%] of those with bipolar disorder, and 36 [48.0\%] of those with depression) $\left(\chi^{2}=0.8, \mathrm{df}=2\right.$, n.s. $)$.

\section{Diagnostic Differences in the Duration of Untreated Psychosis}

The interval from the onset of the first psychotic symptom to the date of first hospitalization (duration of untreated psychosis) (figure 1) differed significantly by diagnosis. Kaplan-Meier estimates of the survival functions of the three diagnostic groups were used to evaluate differences in the survival time to hospitalization among the groups. The median time to hospitalization was 98 days $(95 \%$ confidence interval $[\mathrm{CI}]=36.3-$ 159.7) for the patients with schizophrenia or schizoaffective disorder, 9 days $(95 \% \mathrm{CI}=5.7-12.3)$ for those with bipolar disorder, and 22 days $(95 \% \mathrm{CI}=6.6-37.4)$ for those with depression. All of the pair-wise comparisons of the survival functions of the three groups, according to the log rank test $(\mathrm{df}=1)$, were significant $\left(\chi^{2}=55.2, p<0.0001\right.$, for schizophrenia versus bipolar disorder; $\chi^{2}=13.8, p<0.001$, for schizophrenia versus depression; $\chi^{2}=11.1, p<0.001$, for bipolar disorder versus major depressive disorder).

As table 1 shows, 100 (84.0\%) of the patients with bipolar disorder were hospitalized within 4 weeks of the onset of their psychosis; $33(27.7 \%)$ were hospitalized within 3 days, and $53(44.5 \%)$ were hospitalized within 7 days (data not shown). Only $19(16.0 \%)$ of the patients with bipolar disorder were hospitalized after an interval of greater than 4 weeks. Thirty-eight $(50.7 \%)$ of the patients with psychotic depression were hospitalized within 4 weeks of onset of psychosis (nine [12.0\%] were hospitalized within 3 days; 19 [25.3\%] were hospitalized within 7 days). In the schizophrenia 
FIGURE 1. Years From First Psychotic Symptom to First Hospitalization for 349 Patients in the Suffolk County Psychosis Project, by Diagnosis

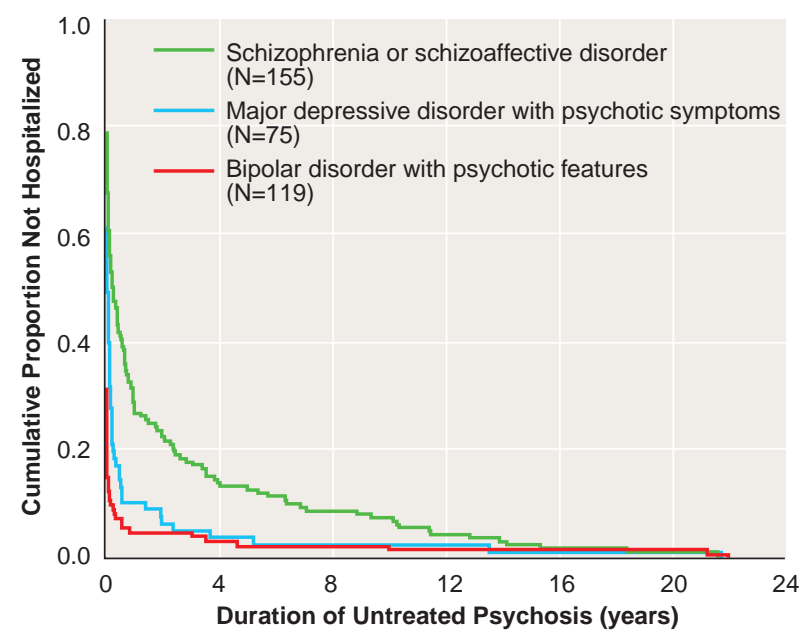

group, $64(41.3 \%)$ experienced their first psychotic symptom more than 6 months before being hospitalized. Of the 45 people whose first psychotic symptom occurred more than 1 year earlier, 10 reported the symptom as occurring 1-2 years before hospital admission and 35 reported that their first symptom occurred more than 2 years before admission.

The association of demographic variables (race, marital status, age at hospitalization, sex, education, and occupational class of head of house) with duration of untreated psychosis was tested by applying a stepwise Cox proportional hazards model that controlled for diagnosis. Only age was significantly associated with the duration interval (Wald $\chi^{2}=4.6, \mathrm{df}=1, \mathrm{p}<$ $0.03)$ : a 1 -year increase in age resulted in a $3.3 \%$ decrease in the hazard function. The significance levels for the remaining five variables ranged from $p=0.21$ for race to $p=0.71$ for household occupational class.

\section{Duration of Untreated Psychosis and 24-Month Outcome and Course}

The 2-year course of illness was generally poor for the patients with schizophrenia or schizoaffective disorder: only $21(14.1 \%)$ of the 149 patients for whom data were available achieved a period of complete remission, $77(51.7 \%)$ had an incomplete remission, and $51(34.2 \%)$ were rated as continually psychotic. Figure 2 shows the Kaplan-Meier estimates of the survival functions of these patterns. The median durations of untreated psychosis for those with complete, partial, and no remission were 59 days $(95 \% \mathrm{CI}=0-213.0), 75$ days $(95 \% \mathrm{CI}=15.8-134.2)$, and 135 days $(95 \% \mathrm{CI}=$ 5.6-264.5), respectively. None of the pair-wise comparisons with the log rank test $(\mathrm{df}=1)$ was significant (for full versus partial remission, $\chi^{2}=0.19, p=0.67$; for full versus no remission, $\chi^{2}=1.70, p=0.19$; and for partial versus no remission, $\chi^{2}=0.85, \mathrm{p}=0.36$ ).
TABLE 1. Interval Between First Psychotic Symptom and First Hospitalization for $\mathbf{3 4 9}$ Patients in the Suffolk County Psychosis Project, by Diagnosis ${ }^{a}$

\begin{tabular}{|c|c|c|c|c|c|c|}
\hline \multirow[b]{2}{*}{ Interval } & \multicolumn{2}{|c|}{$\begin{array}{l}\text { Schizophrenia or } \\
\text { Schizoaffective } \\
\text { Disorder } \\
(\mathrm{N}=155)\end{array}$} & \multicolumn{2}{|c|}{$\begin{array}{l}\text { Psychotic } \\
\text { Bipolar } \\
\text { Disorder } \\
(\mathrm{N}=119)\end{array}$} & \multicolumn{2}{|c|}{$\begin{array}{c}\text { Psychotic } \\
\text { Depression } \\
(\mathrm{N}=75)\end{array}$} \\
\hline & $\mathrm{N}$ & $\%$ & $\mathrm{~N}$ & $\%$ & $\mathrm{~N}$ & $\%$ \\
\hline$<4$ weeks & 48 & 31.0 & 100 & 84.0 & 38 & 50.7 \\
\hline 4 weeks to 6 months & 43 & 27.7 & 10 & 8.4 & 25 & 33.3 \\
\hline$>6$ months to 1 year & 19 & 12.3 & 3 & 2.5 & 4 & 5.3 \\
\hline$>1$ year & 45 & 29.0 & 6 & 5.0 & 8 & 10.7 \\
\hline
\end{tabular}

FIGURE 2. Years From First Psychotic Symptom to First Hospitalization for 149 Patients With Schizophrenia or Schizoaffective Disorder in the Suffolk County Psychosis Project, by Remission Status at 24 Months

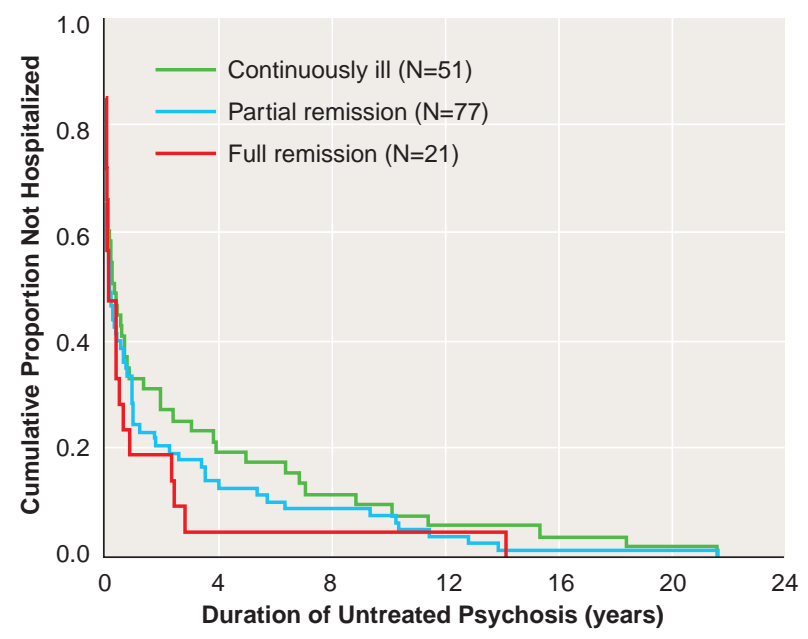

As shown in table 2, there was no significant association between clinical functioning at 24-month follow-up and duration of untreated schizophrenia or schizoaffective disorder when the durations were stratified into three groups-less than 4 weeks, 4 weeks to 1 year, and greater than 1 year-except for a trend for the shortest duration group to have higher BPRS anxious/depressed scores and Hamilton depression scores $(\mathrm{p}<0.05)$.

Overall, $93(80.2 \%)$ of the 116 patients with psychotic bipolar disorder for whom remission data were available achieved complete remission during the 24month follow-up, $18(15.5 \%)$ achieved only partial remission, and five $(4.3 \%)$ were continually ill. The median duration of untreated psychosis was 9 days $(95 \%$ $\mathrm{CI}=5.7-12.3)$ for the complete remission group and 14 days $(95 \% \mathrm{CI}=10.9-17.1)$ for the partial and no remission groups combined (log rank test, $\chi^{2}=0.47, \mathrm{df}=1, \mathrm{p}=$ 0.49 ). Duration of untreated psychotic bipolar disorder was stratified into less than 1 week (0 to 6 days), 1 to 2 weeks ( 7 to 14 days), and more than 2 weeks ( 15 days or more), and no significant differences were found in 24-month functioning (table 2). 
TABLE 2. Association Between Duration of Untreated Psychosis and 24-Month Outcomes for 349 Patients in the Suffolk County Psychosis Project

\begin{tabular}{|c|c|c|c|c|c|c|c|c|c|}
\hline \multirow[t]{3}{*}{ Diagnosis and Outcome Measure } & \multicolumn{6}{|c|}{ Duration of Untreated Psychosis } & \multicolumn{3}{|c|}{ Analysis } \\
\hline & \multicolumn{2}{|c|}{$\begin{array}{l}<4 \text { weeks } \\
(N=48)\end{array}$} & \multicolumn{2}{|c|}{$\begin{array}{c}4 \text { weeks to } 1 \text { year } \\
(N=62)\end{array}$} & \multirow[b]{2}{*}{$N$} & \multirow[b]{2}{*}{$\%$} & \multirow[b]{2}{*}{$\chi^{2}$} & \multirow[b]{2}{*}{$d f$} & \multirow[b]{2}{*}{$p$} \\
\hline & $N$ & $\%$ & $N$ & $\%$ & & & & & \\
\hline \multicolumn{10}{|l|}{ Schizophrenia or schizoaffective disorder } \\
\hline Rehospitalized $(\mathrm{N}=83)$ & 27 & 56.3 & 36 & 58.1 & 20 & 44.4 & 2.15 & 2 & n.s. \\
\hline Course & & & & & & & 2.40 & 4 & n.s. \\
\hline Full remission $(\mathrm{N}=21)^{\mathrm{a}}$ & 6 & 13.0 & 11 & 18.3 & 4 & 9.3 & & & \\
\hline Partial remission $(\mathrm{N}=77)^{\mathrm{a}}$ & 26 & 56.5 & 29 & 48.3 & 22 & 51.2 & & & \\
\hline No remission $(\mathrm{N}=51)^{\mathrm{a}}$ & 14 & 30.4 & 20 & 33.3 & 17 & 39.5 & & & \\
\hline & Mean & $S D$ & Mean & $S D$ & Mean & $S D$ & $F$ & $d f$ & $p$ \\
\hline \multicolumn{10}{|l|}{ Clinical rating } \\
\hline Global Assessment of Functioning Scale & 39.7 & 10.4 & 39.5 & 14.0 & 36.1 & 9.5 & 1.16 & 2,129 & n.s. \\
\hline Scale for the Assessment of Negative Symptoms & 1.9 & 0.8 & 2.0 & 0.8 & 2.0 & 0.8 & 0.35 & 2,112 & n.s. \\
\hline $\begin{array}{l}\text { Scale for the Assessment of Positive Symptoms } \\
\text { BPRS }\end{array}$ & 0.7 & 0.8 & 0.8 & 0.9 & 0.8 & 0.8 & 0.26 & 2,112 & n.s. \\
\hline Thought disturbance & 1.8 & 0.8 & 1.8 & 0.9 & 0.8 & 1.0 & 0.04 & 2,112 & n.s. \\
\hline Anxious/depressed & 1.9 & 0.8 & 1.5 & 0.5 & 1.7 & 0.6 & 4.37 & 2,112 & $<0.05$ \\
\hline Grandiosity & 1.5 & 1.1 & 1.3 & 1.0 & 1.5 & 1.2 & 0.26 & 2,112 & n.s. \\
\hline Excitement & 1.2 & 0.5 & 1.1 & 0.2 & 1.2 & 0.7 & 1.25 & 2,112 & n.s. \\
\hline Hamilton depression scale & 9.9 & 5.5 & 7.7 & 4.2 & 7.3 & 4.9 & 3.07 & 2,107 & 0.05 \\
\hline \multirow[t]{3}{*}{ Beck Hopelessness Scale } & 4.9 & 4.4 & 4.3 & 3.9 & 3.7 & 3.3 & 0.94 & 2,115 & n.s. \\
\hline & \multicolumn{2}{|c|}{$\begin{array}{l}0 \text { to } 6 \text { days } \\
(N=47)\end{array}$} & \multicolumn{2}{|c|}{$\begin{array}{l}7 \text { to } 14 \text { days } \\
(N=30)\end{array}$} & \multicolumn{2}{|c|}{$\begin{array}{l}\geq 15 \text { days } \\
(N=42)\end{array}$} & & & \\
\hline & $N$ & $\%$ & $N$ & $\%$ & $N$ & $\%$ & $\chi^{2}$ & $d f$ & $p$ \\
\hline Psychotic bipolar disorder & & & & & & & & & \\
\hline Rehospitalized $(\mathrm{N}=39)$ & 12 & 25.5 & 10 & 33.3 & 17 & 40.5 & 2.25 & 2 & n.s. \\
\hline Course & & & & & & & 1.85 & 2 & n.s. \\
\hline Full remission $(\mathrm{N}=93)^{\mathrm{a}}$ & 37 & 82.2 & 25 & 86.2 & 31 & 73.8 & & & \\
\hline Partial or no remission $(\mathrm{N}=23)^{\mathrm{a}}$ & 8 & 17.8 & 4 & 13.8 & 11 & 26.2 & & & \\
\hline & Mean & $S D$ & Mean & $S D$ & Mean & $S D$ & $F$ & $d f$ & $p$ \\
\hline Clinical rating & & & & & & & & & \\
\hline Global Assessment of Functioning Scale & 58.1 & 16.1 & 62.3 & 13.5 & 59.0 & 13.4 & 0.71 & 2,100 & n.s. \\
\hline Scale for the Assessment of Negative Symptoms & 0.5 & 0.6 & 0.4 & 0.5 & 0.6 & 0.7 & 0.21 & 2,83 & n.s. \\
\hline Scale for the Assessment of Positive Symptoms & 0.3 & 0.5 & 0.1 & 0.5 & 0.5 & 0.8 & 1.88 & 2,83 & n.s. \\
\hline BPRS & & & & & & & & & \\
\hline Thought disturbance & 1.4 & 0.7 & 1.3 & 0.7 & 1.7 & 0.6 & 0.48 & 2,83 & n.s. \\
\hline Anxious/depressed & 1.6 & 0.6 & 1.6 & 0.7 & 1.7 & 0.6 & 0.23 & 2,83 & n.s. \\
\hline Grandiosity & 1.7 & 1.1 & 1.6 & 1.4 & 1.7 & 1.4 & 0.05 & 2,83 & n.s. \\
\hline Excitement & 1.6 & 1.1 & 1.7 & 1.0 & 1.5 & 1.0 & 0.12 & 2,83 & n.s. \\
\hline Hamilton depression scale & 4.5 & 4.3 & 4.5 & 4.6 & 6.1 & 5.6 & 1.03 & 2,84 & n.s. \\
\hline Beck Hopelessness Scale & 2.3 & 1.9 & 1.4 & 2.3 & 3.0 & 3.3 & 2.60 & 2,93 & n.s \\
\hline & $\begin{array}{l}0 \text { to } 1 \\
(N=\end{array}$ & $\begin{array}{l}\text { days } \\
\text { 25) }\end{array}$ & 15 to & $\begin{array}{l}\text { days } \\
\text { 4) }\end{array}$ & $\begin{array}{r}>90 \\
(N=\end{array}$ & $\begin{array}{l}\text { lays } \\
\text { (6) }\end{array}$ & & & \\
\hline & $N$ & $\%$ & $N$ & $\%$ & $N$ & $\%$ & $\chi^{2}$ & $d f$ & $p$ \\
\hline Psychotic depression & & & & & & & & & \\
\hline Rehospitalized (N=22) & 5 & 20.0 & 10 & 29.4 & 7 & 43.8 & 2.66 & 2 & n.s. \\
\hline Course & & & & & & & 2.43 & 2 & n.s \\
\hline Full remission $(\mathrm{N}=45)^{\mathrm{a}}$ & 19 & 75.0 & 22 & 64.7 & 8 & 50.0 & & & \\
\hline Partial or no remission $(\mathrm{N}=25)^{\mathrm{a}}$ & 6 & 25.0 & 12 & 35.3 & 8 & 50.0 & & & \\
\hline & Mean & $S D$ & Mean & $S D$ & Mean & $S D$ & $F$ & $d f$ & $p$ \\
\hline Clinical rating & & & & & & & & & \\
\hline Global Assessment of Functioning Scale & 59.7 & 16.1 & 53.7 & 15.3 & 52.4 & 15.4 & 1.06 & 2,56 & n.s. \\
\hline Scale for the Assessment of Negative Symptoms & 0.6 & 0.8 & 0.8 & 0.8 & 0.8 & 0.7 & 0.40 & 2,49 & n.s. \\
\hline $\begin{array}{l}\text { Scale for the Assessment of Positive Symptoms } \\
\text { BPRS }\end{array}$ & 0.2 & 0.3 & 0.2 & 0.3 & 0.2 & 0.3 & 0.30 & 2,49 & n.s. \\
\hline Thought disturbance & 1.1 & 0.3 & 1.2 & 0.4 & 1.2 & 0.6 & 0.43 & 2,49 & n.s. \\
\hline Anxious/depressed & 1.9 & 1.1 & 2.0 & 1.1 & 2.2 & 1.2 & 0.16 & 2,49 & n.s. \\
\hline Grandiosity & 1.2 & 0.7 & 1.2 & 0.6 & 1.5 & 1.5 & 0.45 & 2,49 & n.s. \\
\hline Excitement & 1.1 & 0.5 & 1.2 & 0.6 & 1.0 & 0.0 & 0.77 & 2,49 & n.s. \\
\hline Hamilton depression scale & 4.1 & 5.6 & 7.3 & 6.4 & 7.2 & 6.9 & 1.50 & 2,54 & n.s. \\
\hline Beck Hopelessness Scale & 3.3 & 2.6 & 3.1 & 3.8 & 6.8 & 4.8 & 4.50 & 2,100 & $<0.05$ \\
\hline
\end{tabular}

a Group sizes vary because of missing observations. 
In the group of 70 patients with psychotic depression for whom remission data were available, 45 (64.3\%) achieved a period of complete remission, $16(22.9 \%)$ had partial remission, and nine $(12.9 \%)$ were continually ill. The median duration of untreated psychosis was 21 days $(95 \% \mathrm{CI}=5.0-37.0)$ for the complete remission group and 60 days $(95 \% \mathrm{CI}=24.5-95.5)$ for the partial and no remission groups combined $\left(\chi^{2}=\right.$ 3.08, $p=0.08, \log$ rank test). As shown in table 2 , the duration of untreated psychosis for the patients with psychotic depression was divided into 2 weeks or less ( 0 to 14 days), 15 to 90 days, and more than 90 days; no significant differences in outcome at 24-month follow-up were found except for a trend $(\mathrm{p}<0.05)$ for the longest duration group to have higher Beck Hopelessness Scale scores.

\section{DISCUSSION}

The present report is unique in examining the association of duration of untreated psychosis with outcome in both schizophrenia and the affective psychoses. We also used several outcome measures, as suggested by Meltzer (19), rather than a single measure of remission or relapse as used in some earlier reports $(6,9)$. In addition, the generalizability of our findings is enhanced by the epidemiologic nature of the study design and the longitudinal perspective regarding diagnosis.

Our major findings can be summarized as follows: 1) duration of untreated psychosis was longest for individuals with schizophrenia and briefest for the patients with bipolar disorder, and 2) duration of untreated psychosis was not associated with illness course or with other aspects of clinical functioning at 24-month follow-up for any diagnostic group.

Our findings of no association between duration of untreated psychosis and a variety of outcome measures differ from some previous reports. The only previous prospective studies of duration of untreated psychosis for first admissions of patients with schizophrenia used non-DSM-III or DSM-IV diagnostic criteria $(9,20)$ or included subjects with schizophreniform diagnosis (12, 21; unpublished 1994 paper by G.L. Haas et al.), which confers a better outcome than schizophrenia or schizoaffective disorder. Thus, our findings support suggestions $(4,5)$ that the inclusion of a 6 -month duration of illness criterion for DSM-III-R and, subsequently, DSM-IV diagnoses would eliminate much if not all of the predictive effect seen in earlier studies of onset of psychosis. Although three studies $(12,21$; unpublished 1994 paper by G.L. Haas et al.) included patients with schizophreniform disorder, there were only seven such cases in our series, and only four of these had not had previous antipsychotic medication treatment. The duration intervals for these four patients were $3,11,34$, and 55 days.

Another aspect of illness onset relevant to schizophrenia is the existence of a prodromal period preceding the onset of frank psychotic symptoms. It is possi- ble that some previous studies included softer subthreshold symptoms in their definition and that part of the predictive value of duration of untreated psychosis derives in part from the duration characteristics of the prodrome. Using our definition, we found that there is considerable overlap in the confidence intervals of the median survival times of the schizophrenia group when stratified by remission status. Moreover, the medians of the full remission and continuously ill groups differed by only 2.5 months. It is also important to note that $34(66.7 \%)$ of the continuously ill patients had a duration of untreated psychosis of less than 1 year, which is shorter than the duration found in many previous studies.

In addition, earlier studies tended to include subjects who had received previous antipsychotic outpatient treatment, especially among those with extended duration of untreated psychosis, which could have biased that subsample toward greater treatment resistance (22). Also, different outcome measures (e.g., time to remission versus time to relapse) have produced different results in the same study sample $(9,10)$, suggesting the need for multiple outcome measures. Two of the previous prospective studies that found differences in time to relapse $(6,20)$ and time to remission $(9)$ included a treatment trial component (placebo controlled) $(6,20)$ and treatment algorithm (9), which may have affected outcome in ways different from our naturalistic epidemiologic approach. In this regard, for example, we were unable to examine time to remission as a variable because a large proportion of our subjects with schizophrenia in all three duration-of-untreatedpsychosis groups failed to achieve any remission during the 2-year follow-up. This finding is in sharp distinction to the outcome found by Loebel et al. (9) using a treatment algorithm; they found that almost threequarters of their subjects achieved full remission by 2 years. Finally, Anzai et al. (23), using a prospective approach, found later antipsychotic treatment to be significantly associated with increased relapses at 5 -year follow-up; however, they excluded about one-quarter of their initial sample because they had poor outcome.

In regard to the patients with affective psychoses, we are aware of only one previous study that examined this patient population (24). This study, which used RDC to diagnose a small sample of patients $(\mathrm{N}=19)$, also found no association between duration of untreated psychosis and outcome. Our larger sample sizes, differentiation of patients with bipolar disorder from those with major depression, and examination of multiple outcome indexes rather than only remission or relapse strengthen our findings and lend support to the conclusion that the longer presence of psychosis per se (independent of diagnosis) does not predict worse outcome in first-admission psychosis.

To be consistent with previous studies, we operationalized duration of untreated psychosis as the interval between the first psychotic symptom and hospital admission, focusing only on patients with no previous antipsychotic treatment. There are two problems with 
this definition of untreated psychosis. First, it assumes that the interval was one in which the psychosis was persistent. However, it is extremely difficult to calculate the actual duration of untreated psychosis because the information about this period is typically obtained retrospectively. The second problem is that it assumes that the hospital treatment involved "effective" treatment. Although some patients were recovered by the time they were discharged, clearly many were not. Moreover, many patients were rehospitalized relatively soon after their first inpatient stay or never achieved a period of complete remission from their psychotic symptoms. Some other patients discontinued treatment after discharge or took medications sporadically.

One limitation of our study is its reliance on patient self-report for many of the variables. However, several methodological strategies were implemented to maximize reliability. First, the interviewers were experienced clinicians who used well-documented instruments, such as the SCID (13), to collect crucial data elements. Second, the major diagnostic and outcome variables were subjected to a rigorous consensus-based best-estimate procedure, which involved intensive review of study data by at least two research psychiatrists (14). Our definition of crucial variables was based on procedures used in earlier studies. For example, our assessment of onset of psychosis used the SCID to identify the earliest psychotic symptom and to date its occurrence, similar to the method cited by Larsen et al. (22). In addition, verification was obtained from both the patient's significant other and from records of treating facilities wherever possible, similar to the method of Haas and Sweeney (25).

For the patients with schizophrenia, the distribution of duration of untreated psychosis was similar to the distributions reported in earlier studies. One exception is the report by Haas and Sweeney (25), who found that $56.2 \%$ of patients with first-episode schizophrenia had a duration of untreated psychosis greater than 1 year. In addition, the cumulative 2-year relapse rate of $53.7 \%$ cited by Robinson et al. (10) is very similar to our rehospitalization rate of $53.5 \%$ for individuals with schizophrenia. Thus, our methodology and distributions suggest reasonable comparability with earlier studies, lending confidence to our results.

In summary, our results failed to support the contention that a longer exposure to psychotic symptoms per se leads to a worse clinical outcome. Although our findings demand replication in other heterogeneous epidemiologic samples, at face value they do not support the suggestion of a psychotoxic effect exerted by prolonged exposure to psychosis.

\section{REFERENCES}

1. Bromet E, Harrow M, Kasl S: Premorbid functioning and outcome in schizophrenics. Arch Gen Psychiatry 1974; 30:203207

2. Stephens JH, Astrup C, Mangrum JC: Prognostic factors in recovered and deteriorated schizophrenics. Am J Psychiatry 1966; 122:1116-1121
3. Jablensky A, Sartorius N, Ernberg G, Anker M, Korten A, Cooper JE, Day R, Bertelsen A: Schizophrenia: manifestations, incidence and course in different cultures: a World Health Organization ten-country study. Psychol Med Monogr Suppl 1992; 20:1-97

4. Herron WG: Evaluating the process-reactive dimension. Schizophr Bull 1987; 13:357-359

5. Harrow M, Westermeyer JF: Process-reactive dimension and outcome for narrow concepts of schizophrenia. Schizophr Bull $1987 ; 13: 361-367$

6. Crow TJ, MacMillan JF, Johnson AL, Johnstone EC: A randomized controlled trial of prophylactic neuroleptic treatment. Br J Psychiatry 1986; 148:120-127

7. May PRA, Tuma AH, Dixon WJ, Yale C, Thiele DA, Kraude WH: Schizophrenia: a follow-up study of the results of five forms of treatment. Arch Gen Psychiatry 1981; 38:776-784

8. Carpenter WT Jr, McGlashan TH, Strauss JS: The treatment of acute schizophrenia without drugs: an investigation of some current assumptions. Am J Psychiatry 1977; 134:14-20

9. Loebel AD, Lieberman JA, Alvir JMJ, Mayerhoff DI, Geisler $\mathrm{SH}$, Szymanski SR: Duration of psychosis and outcome in first-episode schizophrenia. Am J Psychiatry 1992; 149: 1183-1188

10. Robinson D, Woerner MG, Alvir JM, Bilder R, Goldman R, Geisler S, Koreen A, Sheitman D, Chakos M, Mayerhoff D, Lieberman JA: Predictors of relapse following response from a first episode of schizophrenia or schizoaffective disorder. Arch Gen Psychiatry 1999; 56:241-247

11. Rothman KF, Michels KD: The continuing unethical use of placebo controls. N Engl J Med 1994; 331:394-398

12. Edwards J, Maude D, McGorry P, Harrigan SM, Cocks JT: Prolonged recovery in first-episode psychosis. Br J Psychiatry 1998; 172(suppl 33):107-116

13. Spitzer RL, Williams JBW, Gibbon M, First MB: The Structured Clinical Interview for DSM-III-R (SCID), I: history, rationale, and description. Arch Gen Psychiatry 1992; 49:624-629

14. Fennig S, Craig T, Lavelle J, Kovasznay B, Bromet EJ: Bestestimate versus structured interview-based diagnosis in first admission psychosis. Compr Psychiatry 1994; 35:341-348

15. Andreasen NC, Arndt S, Alliger R, Miller D, Flaum M: Symptoms of schizophrenia: methods, meanings, and mechanisms. Arch Gen Psychiatry 1995; 52:341-351

16. Woerner M, Manuzza S, Kane J: Anchoring the BPRS: an aid to improved reliability. Psychopharmacol Bull 1988; 24:112124

17. Hamilton M: A rating scale for depression. J Neurol Neurosurg Psychiatry 1960; 23:56-62

18. Beck AT, Weissman A, Lester D, Trexler L: The measurement of pessimism: the Hopelessness Scale. J Consult Clin Psychol $1974 ; 42: 861-865$

19. Meltzer HY: Treatment of the neuroleptic-nonresponsive schizophrenic patient. Schizophr Bull 1992; 18:515-542

20. Johnstone EC, Crow TJ, Johnson AL, MacMillan JF: The Northwick Park study of first episodes of schizophrenia, I: presentation of the illness and problems relating to admission. $\mathrm{Br}$ J Psychiatry 1986; 148:115-120

21. Coryell W, Tsuang MT: DSM-III schizophreniform disorder: comparisons with schizophrenia and affective disorder. Arch Gen Psychiatry 1982; 39:66-69

22. Larsen TK, McGlashan TH, Moe LC: First-episode schizophrenia, I: early course parameters. Schizophr Bull 1996; 22: 241-256

23. Anzai N, Okazaki Y, Miyauchi M, Harada S-I, Kan Y, Sasaki T, Kumagai N, Shikiba N, Iwanomi A, lida S, Hiramatsu K-I, Niwa S-I, Otha M: Early neuroleptic medication within one year after onset can reduce risk of later relapses in schizophrenic patients. Annual Report of the Pharmacopsychiatric Research Foundation 1988; 19:258-265

24. Rabiner CJ, Wegner JT, Kane JM: Outcome study of first-episode psychosis, I: relapse rates after 1 year. Am J Psychiatry 1986; 143:1155-1158

25. Haas GL, Sweeney JA: Premorbid and onset features of first episode schizophrenia. Schizophr Bull 1992; 18:373-386 